\title{
CRIMSONpublishers
}

http://www.crimsonpublishers.com

Case Report Surg Med Open Acc J

\section{Large Spigelian Hernia}

\section{Devaji Rao $S^{*}$}

Senior Consultant Surgeon, Dhanwanthri Surgical Clinic and St. Isabel's Hospital, India

*Corresponding author: Devaji Rao S, Senior Consultant Surgeon, Dhanwanthri Surgical Clinic and St. Isabel's Hospital, India

Submission: December 13, 2017; Published: January 19, 2018

\begin{abstract}
Spigelian hernias form a minority of all abdominal wall hernias. They occur between the layers of the abdominal wall, i.e. between the transversus abdominis and the internal oblique muscles through a small slit like or oval defect and may become incarcerated. A variety of intra abdominal organs have been reported in the hernia sac. Obstruction and strangulation are potential complications but they are rare. The clinical diagnosis of a Spigelian hernia is difficult when it is small. We present here a large Spigelian hernia which persisted for very many years without any complications.
\end{abstract}

Keywords: Hernia; Spigelian hernia

Abbreviations: TEP: Totally Extraperitoneal; TAPP: Transabdominal Preperitoneal

\section{Introduction}

Spigelian hernias generally appear within what is referred to as the "Spigelian hernia belt", that is an area demarcated by a horizontal line at the level of the umbilicus and another line below which joins the two anterior superior iliac crests. The Spigelian hernias are found at the lateral edge of the rectus abdominis muscle. They are rare and can be difficult to discern clinically. CT scans and ultrasonography can be useful in their detection. Early surgery is indicated as they are prone to complications due to their position and their narrow neck.

\section{Case Report}

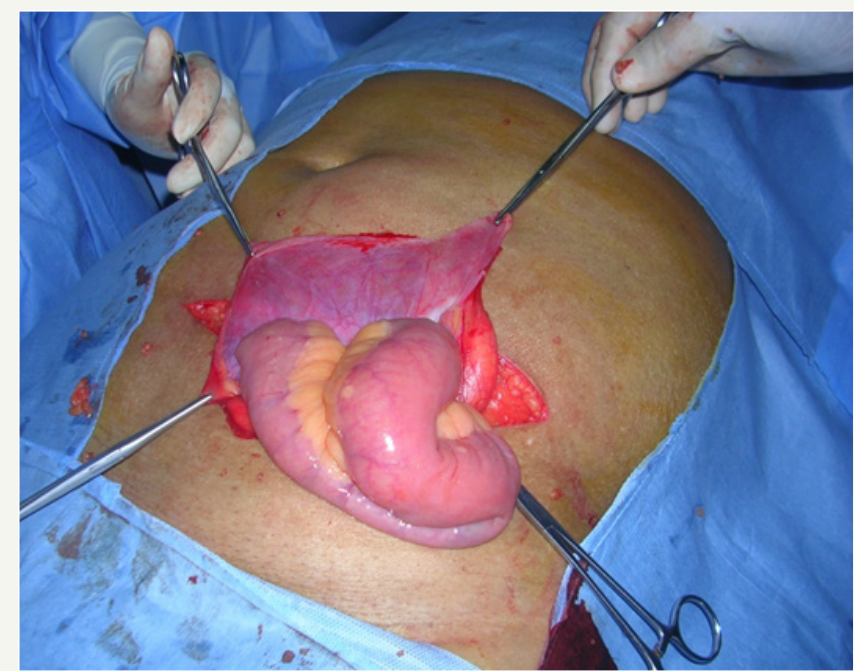

Figure 1: CT - Large left sided Spigelian hernia.

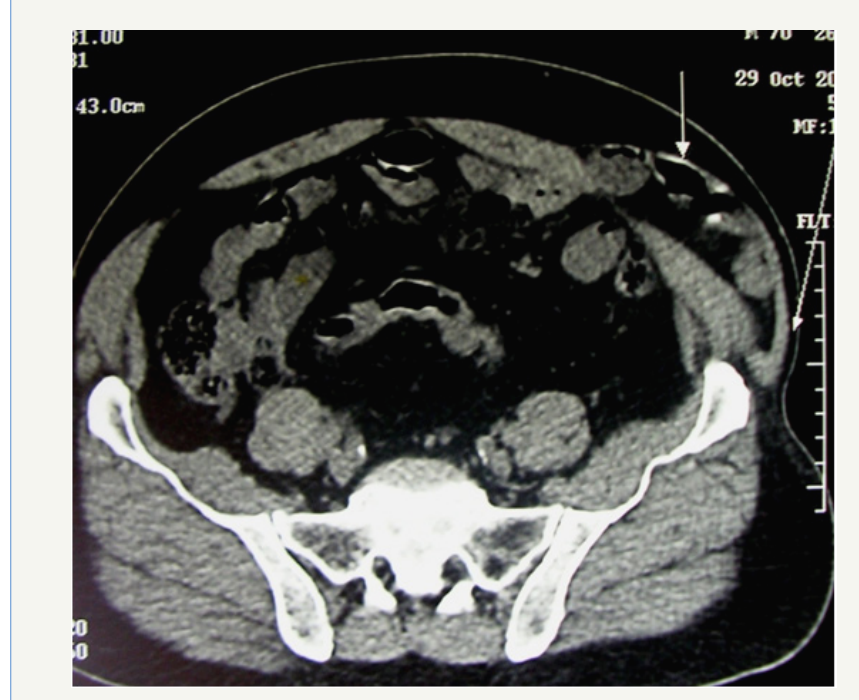

Figure 2: Operative photograph of Spigelian hernia.

A 75 year old male presented with a swelling in the left lower abdomen which has gradually increased in size over the last 12 years. Mild pain, especially on physical strain was present for the previous 1 year, without associated vomiting, constipation or urinary symptoms. On examination, there was an oblong swelling in the left lower abdomen measuring about $20 \mathrm{~cm}$ transversely $X 10 \mathrm{~cm}$ vertically, starting from the lateral margin of the left rectus abdominis, which was soft and mildly tender with cough impulse. Bowel sounds could be heard within the swelling. A clinical diagnosis of large Spigelian hernia was made, confirmed by ultrasonography and CT scan (Figure 1), which revealed a defect in 
the abdominal wall, at about $6 \mathrm{~cm}$ below the level of the umbilicus near the lateral margin of the left rectus abdominis. At surgery, the skin flaps were raised through a transverse incision over the swelling and bulging of the external oblique aponeurosis was seen. This aponeurosis was incised along the direction of its fibres, the sac isolated and opened to find healthy small intestines in it (Figure 2), which was reduced into the abdomen without difficulty. Excess sac was resected, and the defect which was about $6 \mathrm{~cm}$ horizontally and $1 \mathrm{~cm}$ vertically was closed with polyglactin sutures and reinforced with polypropylene mesh, fixed on the internal oblique muscle, as the transversus abdominis was thin and supple probably due to advanced age. The external oblique aponeurosis was approximated over the mesh. The wound was closed in layers and the patient had an uneventful recovery.

\section{Discussion}

Spigelian hernias are very uncommon and constitute only about $0.12 \%$ of all abdominal wall hernias [1]. They appear between the $4^{\text {th }}$ and $7^{\text {th }}$ decades with a slight female preponderance [2]. A Spigelian hernia is defined as the protrusion of preperitoneal fat, peritoneal sac, and or organs through a congenital or acquired defect in the Spigelian aponeurosis.

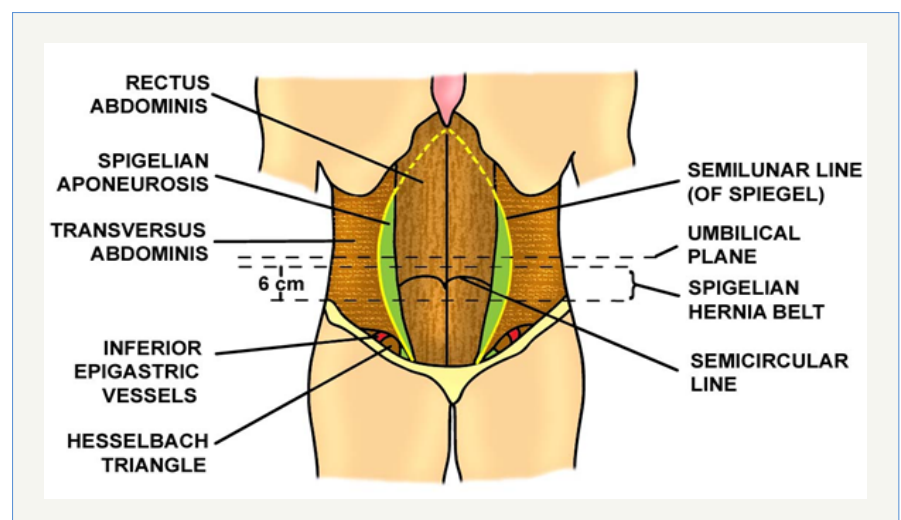

Figure 3: Anatomy of abdominal wall.

Although named after Adriaan van der Spieghel (1578 - 1625), a Belgian anatomist (who only described the semilunar line - linea Spigeli), it was Henry-Francis Le Drain who described a spontaneous rupture along the semilunar line in 1742 . However, it was Josef T K Klinkosch in 1764 who described the Spigelian hernia as a defect in the semilunar line [3]. The line of Spigel marks the transition of the muscle to aponeurosis in the transversus abdominis muscle. The part of the aponeurosis which lies between the lateral border of the rectus abdominis and the semilunar line is called the Spigelian aponeurosis (Figure 3). The semilunar line is a laterally convex line and in its cranial part, lies dorsal to the rectus muscle leaving no space for Spigelian aponeurosis, explaining the small number of Spigelian hernias in this region. In addition, the fibers of the transverus abdominis and of the internal oblique muscles cross one another at right angles, making herniation unlikely in this region, still, a few cases have been reported [4]. Spigelian hernias can occur throughout the length of the Spigelian aponeurosis, but occur more frequently in its widest part, above the interspinous (ASIS) and extending about $6 \mathrm{~cm}$ cephalad, the so called 'Spigelian belt'. The majority (90\%) of Spigelian hernias occur within the Spigelian belt above the inferior epigastric vessels. The Spigelian aponeurosis can also be found caudal and medial to the inferior epigastric vessels i.e. within the Hasselbach's triangle and hernias which occur in this region are called 'Low Spigelian Hernias' and may even be confused with indirect inguinal hernias [2].

The external oblique muscle and its aponeurosis generally remain intact, but a few cases of Spigelian hernias have been reported in which the external oblique aponeurosis is traversed [5]. The hernial orifice is generally small varying from 0.5 to $2 \mathrm{~cm}$ in diameter, oval or slit like in shape, with well defined, firm edges and remains limited to the Spigelian aponeurosis. If the slit enlarges, it does so in a lateral direction, as the medial side extension is limited by the thick rectus abdominis muscle. The sac can also expand laterally below the external oblique aponeurosis and assume a mushroom shape.

In the congenital variety, perforating vessels may weaken the area in the Spigelian aponeurosis and a small lipoma or fat may lead to hernia formation. In the acquired variety, stretching of abdominal wall caused by obesity, multiple pregnancies, previous surgery or scarring may be the etiological causes for herniation.

Embryologically, a Spigelian hernia represents the clinical outcome of weak areas in the extensions of the aponeuroses of layered abdominal muscles, as they develop separately in the mesenchyme of the somatopleura, originating from the invading and fusing myotomes [6]. In its earliest stages, it is simply a protrusion of a peritoneal fat through the Spigelian aponeurosis, but a peritoneal sac is found in most cases. If the hernia sac has a content, it is an intra abdominal organ like omentum or small bowel and rarely the large bowel, stomach, gallbladder, ovary, testis, bladder, Meckel's diverticulum and leiomyoma of uterus are reported. The vermiform appendix as a content is rare [7]. Inflamed appendix, Crohn's appendicitis and incarcerated Meckel's diverticulaum are rarely reported [8]. Incisional hernias through the Spigelian aponeurosis are considered as Spigelian hernias by some authors, but they are not accepted conventionally as Spigelian hernias [9].

Clinically, it may present as a vague mass becoming prominent on standing or straining, with or without pain. The diagnosis of a Spigelian hernia is often difficult, as it has no characteristic symptoms, especially when there is no obvious mass, as it lies interstitially within the parietal wall. Only about $50 \%$ of cases are diagnosed preoperatively [10]. The risk of strangulation is very high, due to the shape and sharp margins of the defect, but only a few cases are reported in the literature [11]. The Richter type of hernia has also been reported in association with a Spigelian hernia. A significant proportion of patients (21\% - 33\%) present with a complication and require an emergency operation [12].

Ultrasonography is useful in identifying a defect and a hernia sac, especially when done in supine and upright positions, while performing a Valsalva maneuver, and Spangen has reported positive diagnosis with ultrasonography in 19 of 24 patients in his series [2]. 
Multislice CT scan is a very useful method to identify small hernias [13], especially when the ultrasonography is equivocal.

The swelling needs to be differentiated from other masses within the abdominal wall like rectus sheath hematomas, parietal abscesses, lipomas, seromas, peritoneal tumor seeding. When a hernia presents with only pain, if should be differentiated from an inflammatory pathology in that region, acute appendicitis if in the right lower abdomen. A low lying Spigelian hernia may be confused with a large inguinal hernia.

Treatment is always surgical, either by open or laparoscopic techniques. Laparoscopic techniques include totally extraperitoneal (TEP) or Transabdominal preperitoneal (TAPP) repairs, with good results [14]. TEP repair is recommended for uncomplicated elective repair and a TAPP repair is recommended when a coexistent intrabdominal pathology is to be handled simultaneously. For emergencies, an open approach is recommended for Spigelian hernia repair. We used an open approach and encountered no difficulty.

\section{Conclusion}

Spigelian hernias are difficult to diagnose clinically, because of their vague clinical presentations. Ultrasound scanning of the semilumar line should be undertaken in all patients with obscure abdominal pain associated with bulging of the abdominal wall in the standing patient [14]. A CT scan with close thin sections is considered the most reliable technique to make the diagnosis in doubtful cases [15]. Early surgery is indicated as such hernias are prone, though rarely, to strangulations.

\section{References}

1. Howlihan TJ (1976) A review of Spigelian hernia. Am J Surg 131: 734 735 .
2. Spangen L (1989) Spigelian hernia. Word J Surg 13(5): 573-580.

3. Klinkosch JT (1764) Programma Quo Divisionem Herniarum, Novumque Hernia Ventralis Specium Propnit. Rotterdam: Benam.

4. Rehman JM, Seow CS, O’Dwyer PJ (2000) A case of a Spigelian hernia at an unusually high anatomical location. J R Coll Surg Edinb 45(3): 196197.

5. Mariolis-Sapsakos T, Kalles V, Papapanagiotou I, et al. (2013) A rare case of Spigelian hernia penetrating the external oblique muscle. OA Case reports 28: 11-13.

6. Skandalakis PN, Zoras O, Skandalakis JE, et al. (2006) Spigelian hernia: surgical anatomy, embryology and technique of repair. Am Surg 72(1): 42-48.

7. Thomasset SC, Villatoro E, Wood S, Martin A, Finlay K, et al. (2010) An unusual Spigelian hernia involving the appendix; a case report. Cases J 3: 22 .

8. Lin PH, Kofforon AJ, Heilizer TJ, Lujan HJ (2000) Right lower quadrant abdominal pain due to appendicitis and an incarcerated Spigelian hernia. Am Surgeon 66(8): 725-727.

9. Malik KA, Chopra P (2006) Spigelian hernia: a rarity. J Pak Med Assoc 56(9): 47-49.

10. Opson RO, Davis WC (1969) Spigelian hernia: Rare or obscure? Am J Surg 116(6): 842-846.

11. Kirby RM (1987) Strangulated Spigelian hernia. Postgraduate Med J 63: 51-52.

12. Artioukh DY, Walker SJ (1996) Spigelian hernia: presentation, diagnosis and treatment. J R Coll Surg Edinb 41(4): 241-243.

13. Papierniak KJ, Wittenstein B, Bartizal JF, Wielgolewski JW, Love L (1983) Diagnosis of Spigelian hernia by computed tomography. Arch Surg 118(1): 109-110.

14. Mittal T, Kumar V, Khullar R, Sharma A, Soni V, et al. (2008) Diagnosis and management of Spigelian hernia: A review of literature and our experience. J Min Access Surg 4(4): 95-98.

15. Campos SM, Walden T (1997) Images in clinical medicine: Spigelian hernia. N Engl J Med 336(16): 1149. 